

\section{LOS PAISAJES DEL TURISMO: UNA PRESENTACIÓN}

Joaquín Sabaté Bel

Ricard Pié es seguramente uno de los mayores estudiosos de la arquitectura y el urbanismo del turismo. Sus trabajos en los años noventa junto con Rosa Barba, constituyen aportaciones seminales en un campo tan necesitado de reflexiones.

En el mismo sentido, la fundación, a finales de 2011, del Instituto de Hábitat, Turismo y Territorio entre las Universidades Politécnica de Cataluña (UPC) y Málaga (UMA), da un nuevo impulso al estudio del espacio turístico en sus diversas escalas (arquitectura, ciudad, territorio y paisaje), al igual que su participación en el Programa de Doctorado en Urbanismo de la UPC.

Por ello nos parece muy pertinente que su artículo "Investigar sobre la arquitectura del turismo. Cuatro notas para no perderse", sea el que abra un número monográfico dedicado a los paisajes del turismo. Nadie mejor que él para dibujar el mapa de las investigaciones sobre el turismo desde nuestra disciplina, las diversas temáticas abordadas, $\mathrm{y}$, muy fundamentalmente, los retos a los que la investigación se enfrenta. Paisajes, arquitecturas, valores culturales y simbólicos y procesos y estrrategias territoriales, son cuatro temáticas que le permiten clasificar el conjunto de textos recogidos en este volumen, que tiene una dimensión y número de colaboradores superior al de anteriores ediciones de QRU, muestra del interés que este campo suscita entre jóvenes estudiantes de nuestro Programa de Doctorado.

Un número doble de QRU, por la aportación tan considerable de estudios, invita a debatir la manera de presentarlos. Biel Horrach observa que pueden encuadrarse en dos grandes familias, donde la primera -La construcción del espacio del turismo de masas- reuniría los siguientes textos:

Alli donde el mar acaba

Costa Brava, los retos urbanisticos del turismo de masas. La huella de la ciudad jardin y algunos principios racionalistas en el tejido turístico de masas

La vida breve de la ciudad de veraneo. Análisis de planes para un turismo residencial: Costa Blanca 1959-1973

Génesis de los tejidos turísticos maduros. El proceso de transformación de la forma urbana de Palmanova-Torrenova de Calviá, Mallorca 
¿La participación ciudadana se ha integrado al proceso de planificación turística en Cancún, México?

Centros Integralmente Planeados (CIPS) en México. El Proyecto Turistico del FONATUR

Mientras que la segunda -La construcción del paisaje turístico-, englobaría estos otros:

Estaciones termales europeas. Entre la ciudad y el territorio

Turismo, paisaje y trazas de cultivo

Revisitando Port Leucate-Barcarès

Prácticas del paisajismo francés: La construcción del proyecto del paisaje en el plan turistico Maspalomas Costa Canaria. 1961

La costruzione dello spazio turistico nella Costa Smeralda: neorealismo o banalizzazione dell'architettura vernacolare?

Il paesaggio del camping nella storia: dall'impatto zero alla colonizzazione intensiva

Se vende o alquila isla. La buisqueda del lugar singular para el turista global.

César Manrique: La conciencia del paisaje

Él mismo nos descubre que, curiosamente, la mitad de los textos se refieren al turismo mediterráneo, mientras que la otra mitad, se situa en territorios atlánticos.

En su artículo introductorio, Ricard Pie sitúa buena parte de los textos aquí incluidos dentro de un preciso mapa de la investigación disciplinar.

A mi me parece, en cambio, igualmente oportuna, otra forma de mostrarlos, verificando el vínculo que en las distintas investigaciones se establece entre turismo, paisaje y urbanismo, como propuse en un artículo reciente. ${ }^{1}$ Porque precisamente, como allí decía, cual amantes ora ciegos, ora despechados, turismo y paisaje han mantenido, a través del urbanismo, una intensa y tantas veces conflictiva relación durante las últimas décadas, desde la ignorancia mutua o la satanización maniquea, hasta reconocerse estrechamente interdependientes. Y esto se refleja claramente en los estudios llevados a cabo por investigadores de nuestro Departamento de Urbanismo y Ordenación del Territorio (DUOT), tanto desde el ejercicio profesional, como desde la reflexión académica. A través del análisis de numerosos planes, proyectos, artículos y tesis doctorales, se pueden reconocer momentos bien diferenciados. Su repaso nos permite destacar avances en el conocimiento disciplinar, pero asimismo importantes retos pendientes. No se trata de etapas estancas,

1 Turismo, paisaje y urbanismo: un diálogo necesario, en ACE año 9, nº 25, (pp. 278-302). Barcelona, junio 2014. 
sino donde las temáticas abordadas, y fundamentalmente, la relación que se establece en cada una de ellas entre turismo, paisaje y urbanismo, dejan poco a poco de ser predominantes, y otras se les van superponiendo, al inicio, y reemplazándolas después, a la manera de los paradigmas de Kuhn. Recogeré parte de lo planteado hace un par de ańos, al objeto de situar en cada periodo los artículos incluidos en este QRU.

En un primer periodo los protagonistas son los planes de ordenación en ámbitos turísticos, particularmente en el litoral de Cataluña y Canarias. Predomina en ellos un considerable esfuerzo de contención de los desarrollos heredados, a los que se considera responsables de la degradación del paisaje. ${ }^{2}$

Tras las propuestas marcadamente expansivas de los años sesenta y de la posterior crisis económica, estos planes se convierten en una iniciativa fundamental en manos de los nuevos ayuntamientos, que apoyan en las intervenciones urbanísticas gran parte de su programa.

Buena parte de su documentación se entretiene en el inventario del nivel de colmatación de las áreas turísticas; en el análisis pormenorizado de la vigencia de planes parciales abusivos y no ejecutados, de los derechos adquiridos por promotores y propietarios y de las posibilidades de desclasificación. Se trata asimismo de conocer la especificidad de lo turístico. De ahí los detallados estudios sobre las tipologías hoteleras y residenciales más comunes en dicha actividad, incluidos los campings; o la atención al diseño de paseos litorales, equipamientos y espacios libres, propios de un urbanismo generalmente asociado al veraneo. Se trata asimismo de dar continuidad y trabazón a la ciudad existente y a la turística, de dotarlas de urbanidad, de redimensionarlas y precisar la contribución de cada iniciativa al patrimonio urbano municipal.

Alguno de los artículos aquí incluidos retratan este proceso de construcción del espacio turístico que aquellos planes pretenden ordenar.

"La construcción del espacio del turismo de masas. Allí donde el mar acaba", recoge parte de la tesis doctoral de Purificación Díaz, donde se aborda el debate sobre la ordenación del litoral español, ámbito donde aparecen los principales desarrollos turísticos en nuestro país. Aunque el objetivo es valorar los problemas y alternativas para ordenar una costa notablemente degradada, constituye un interesante balance de dicho proceso.

2 Especialmente en los planes de Castell-Platja d'Aro, Sant Feliu de Guixols y Santa Cristina d'Aro, del equipo de Rosa Barba y Ricard Pie; o en los de Torroella de Montgrí (Premio Nacional de Urbanismo, 1983), Vidreres, Sant Pere Pescador, Roses; y más adelante en los de Maó, Arona, Santiago del Teide, Granadilla de Abona (estos últimos en la isla de Tenerife), de CCRS Arquitectos (Isabel Castiñeira, Miquel Corominas, Amador Ferrer y Joaquín Sabaté). La Generalitat de Cataluña contribuye a difundir esta línea de trabajo con una colección de publicaciones, denominada Estudios Urbanos, cuyos dos primeros números, en una fecha tan temprana como 1981, están dedicados precisamente a planes realizados en dos áreas turísticas por excelencia en Cataluña: Vall d'Aro y Torroella de Montgrí-L'Estartit. 
El reconocimiento de los terrenos aledaños al mar, otrora minusvalorados; su saneamiento, construcción de accesos, plantaciones, desecación, colonización agrícola y posteriormente turística, con la eclosión del turismo del sol y la playa, son procesos cuyo conocimiento resulta imprescindible para entender mejor las lógicas de ocupación y abordar hoy con rigor la ordenación del litoral.

En un segundo periodo irrumpe con fuerza la convicción de que la razón de ser del turismo es el paisaje. El artículo "Turismo, paisaje y terrazas de cultivo", defiende la reinterpretación morfológica de cada ámbito de intervención, recuperando, en el caso del Plan Insular de Tenerife, técnicas utilizadas un siglo atrás por los habitantes del lugar para esculpir la piedra volcánica, dibujando piscinas naturales, caminos y escaleras de acceso al agua; o creando áreas resguardadas del viento y del sol, con pequeños muros y umbráculos, con técnicas heredadas de la cultura agrícola. Al tiempo plantea una apuesta aún pendiente, desarrollando razones y mecanismos para que el turismo retribuya al paisaje, toda vez que éste constituye su principal razón de ser.

De un tercer periodo, que arranca en el cambio de siglo y se extiende hasta la actualidad, cabe destacar la consolidación de dos líneas de investigación dentro del Programa de Doctorado del DUOT, una donde son objeto de atención especial los espacios del turismo y los procesos y estrategias en los mismos, así como su construcción física, a partir de las denominadas piezas mínimas del turismo ${ }^{3}$; y una segunda centrada en los paisajes culturales ${ }^{4}, y$ por ende, en la relevancia cada vez mayor del denominado turismo cultural.

No hay nada más satisfactorio en un programa de investigación que poder reconocer la irrupción de una nueva generación que da continuidad a los esfuerzos previos. En estos últimos años se ha formado un grupo de jóvenes investigadores dedicados al estudio del turismo desde la perspectiva urbanística. Cada uno de sus trabajos en curso, que se recogen en esta publicación, muestra aspectos, temas y retos de futuro relevantes, en un campo tan actual y fascinante, como necesitado de todos los esfuerzos desde nuestra disciplina.

Aunque sus contenidos son más interdependientes que estancos, cabe reconocer cuatro campos principales. Frente al fatalismo del turismo como depredador del paisaje, o frente a la desconsideración de una arquitectura

3 Ver el artículo de Rosa Barba y Ricard Pié Los nuevos espacios del turismo. Modelos de arquitectura y espacios para la ordenación territorial, en Arquitectura y Turismo: Planes y Proyectos. CRPP y UPC. Barcelona, 1996.

4 Arranca con la fundación del Laboratorio Internacional de Paisajes Culturales y los trabajos realizados conjuntamente con el Massachusetts Institute of Technology (que dan lugar a los libros Designing the Llobregat Corridor. Cultural Landscape and Regional Development y Event Places), y en especial con la Red de Gestión de recursos culturales como fundamento de planes de desarrollo local (en el marco de un proyecto ALFA de la Comisión Europea). Y prosigue con estudios y propuestas de ordenación en territorios cargados de recursos patrimoniales y destino de intereses turísticos como Tierra del Fuego (Chile), Quebrada de Humahuaca (Argentina) o Minas Gerais (Brasil). Incluye asimismo la puesta en valor de los ejes patrimoniales del Llobregat, Ter y Freser. 
turística supuestamente vergonzante, el primero de estos campos pone en valor episodios singulares, en los que se reivindica la singular contribución de dicha arquitectura, que debe enfrentarse a una nueva demanda social: el turismo de masas.

Lo hace Pepe Bru en su tesina y en el texto que reproducimos, "La vida breve de la ciudad de veraneo. Análisis de planes para un turismo residencial: Costa Blanca 1959-1973". Analiza los principales proyectos en la costa alicantina y murciana en el periodo del auge turístico. Narra el proceso de construcción de un ámbito que se especializa en el turismo residencial, y se detiene muy particularmente en las interesantes aportaciones de Antonio Bonet Castellana, Josep Puig Torné, Antonio Orts Orts, Juan Guardiola Gaya, Juan Antonio García Solera o Ricardo Bofill Leví. El esfuerzo por ajustarse orgánicamente a parajes singulares, las zonificaciones funcionales, la jerarquización del viario rodado y peatonal, la diversidad de espacios libres, la incorporación de unidades vecinales, pero muy fundamentalmente, las nuevas tipologías para afrontar una nueva problemática, dibujan un rico panorama de este esfuerzo en el arranque pionero del urbanismo y la arquitectura turísticos, bien alejado de los clichés criticados.

Las investigaciones de Carolina Ramos se centran en el arranque del turismo en la Costa Brava, y muy particularmente, en la construcción de Playa de Aro, una ciudad creada ex-novo para acoger el turismo de masas. En "Costa Brava, los retos urbanísticos del turismo de masas. La huella de la ciudad jardín y algunos principios racionalistas en el tejido turístico de masas" nos muestra este ámbito como un rico territorio de experimentación de dos modelos urbanos opuestos, la ciudad jardín, ya ensayada por el turismo de élite, y la ciudad de los bloques de origen racionalista. Y nos descubre a su vez episodios escasamente conocidos, como la preocupación de la Generalitat republicana por ordenar el litoral (con la Conferencia de la Costa Brava en 1935, o la creación de un Patronato), así como algunos proyectos pioneros (ciudades jardín de Sant Elm en 1922 y S’Agaró entre 1916 y 1932, y muy especialmente el proyecto final de carrera de un poblado de vacaciones para la clase trabajadora de Sert y Torres Clavé (1928), claro antecedente de su más conocida Ciutat del repós i les vacances.

Igualmente Mónica Batalla reivindica el origen ilustre de los primeros enclaves turísticos en "Estaciones termales europeas. Entre la ciudad y el territorio", que se producen al amparo de algunos de los míticos balnearios europeos. Enlazando con la línea de investigación sobre las piezas del turismo, disecciona topologías y tipologías de instalaciones termales y rehaciendo la historia de algunos de ellos, nos los muestra como generadores de singulares espacios turísticos.

También reclama Marilena Lucivero en "Il paesaggio del camping nella storia: dall'impatto zero alla colonizzazione intensiva”, el pedigrí de una ma- 
nifestación tan denostada hoy en día como los campamentos de turismo o campings, pero que tiene su origen en el aprecio por la naturaleza y en su puesta en valor, y se degrada al convertirse en alternativa más económica y desatenta para un turismo masivo.

Un segundo grupo de tesis y estudios se ocupa de episodios bien singulares de ordenación de extensos territorios con destino turístico. La tesis de Guadalupe Aldape y la investigación en curso de Arturo Dávila analizan una experiencia relativamente reciente: la de un país, México, con un riquísimo patrimonio natural y cultural, que pretende ordenar, y a la vez diversificar, su oferta turística. Sus artículos "¿La participación ciudadana se ha integrado al proceso de planificación turística en Cancún, México?” y “Centros Integralmente Planeados (CIPS) en México. El Proyecto Turístico del FONATUR” documentan la aparición del FONATUR (Fondo Nacional de Fomento al Turismo), que pretende posicionar México como un destino turístico mundial, con el potencial de su litoral como punta de lanza, para así utilizar esta industria como motor de cambio y desarrollo para zonas fuertemente deprimidas. Se han desarrollado ya ocho programas y numerosas rutas temáticas, mientras que el FONATUR ha diseñado y construido durante los últimos treinta años varios Centros Integralmente Planeados (Cancún, Huatulco, Ixtapa, Sinaloa, Los Cabos, Loreto, Nayarit y Marina Cozumel). Esta "operación de estado", como lo fue en su día la del Languedoc-Roussillon, muestran las dificultades de reinventar el destino turístico.

En un tercer grupo de tesis y estudios podemos englobar aquellas investigaciones que se ocupan de diseccionar la construcción de territorios eminentemente turísticos, como es el caso de Baleares o de las islas hondureñas y colombianas en el Gran Caribe. Las tesis doctorales de Angélica Ayala y de Biel Horrach, nos muestran la actividad turística como constructora de paisaje y factor fundamental de transformación, al tiempo que agente motor de la economía y con una notable responsabilidad por ello, en el futuro de territorios y sociedades.

En su artículo "Se vende o alquila isla. La búsqueda del lugar singular para el turista global", Angélica Ayala se entretiene en el análisis detenido de territorios insulares de escasa extensión, perdidos en los mapas y olvidados por los gobiernos, pero donde se producen impactos considerables. El estudio le lleva a construir una categoría especial, territorios anfibios, por su relación simbiótica con el mar, pero al tiempo a distinguir en un rico microcosmos, categorías tan diversas, como las que denomina islas en la isla; islas del no turismo; islas en venta y enclaves insulares. Su investigación denuncia la situación de estas pequeñas islas, objeto de compraventa, donde sus habitantes sobreviven a la pobreza; reclama soluciones a un hábitat insular desamparado por sus gobiernos y por las instituciones supranacionales y propone algunas estrategias de acción y una metodología para reconocer los elementos básicos del modelo territorial implícito. 
El artículo de Biel Horrach "Génesis de los tejidos turísticos maduros. El proceso de transformación de la forma urbana de Palmanova-Torrenova de Calviá, Mallorca”, resume parte de su tesis doctoral. Nos muestra la isla de Mallorca como uno de los principales laboratorios para la experimentación del turismo de masas. Lo hace mediante la superposición de tres análisis en los que va modificando el foco temático y la escala de lectura. En el primero distingue como se ha producido la construcción del espacio turístico, estableciendo un símil con el sistema de producción fordista, desde los primeros ensayos, a la ocupación intensiva del litoral, y, finalmente, a una etapa de dispersión turístico-residencial. En el segundo disecciona la especificidad de los tejidos propios de la actividad turística (asentamientos suburbanos vacacionales, extensiones en malla, ciudad jardín y centros autónomos. En el tercero reconoce los sistemas de asentamientos turístico-territoriales.

Las tesis doctorales de Izol Marez, Alessandra Cappai e Iván Álvarez se fijan en otros ejemplos pioneros. Por un lado en la operación Languedoc-Rousillon, donde se consolida la especificidad de una arquitectura del turismo. En "Revisitando Port Leucate-Barcarès", Izol Marez arranca con un enunciado bien explícito, se trata de volver al pasado para entender el presente. Y en este caso analiza documentos originales de aquel espléndido proyecto de Georges Candilis, donde el gobierno francés apuesta por crear un destino singular en un territorio de marismas y fuertes vientos. La autora nos descubre, hurgando en archivos de la época, las notables aportaciones del Team X a la arquitectura y al urbanismo del turismo de masas, y explora posibles influencias de este proyecto en el escenario turístico internacional.

En "La costruzione dello spazio turistico nella Costa Smeralda: neorealismo o banalizzazione dell'architettura vernacolare?", Alessandra Cappai se fija en un episodio coetáneo, de pequeña dimensión y mucho menos difundido, pero no por ello de menor relevancia, la construcción del destino turístico de la Costa Esmeralda en Cerdeña. En este caso la ecuación diseñada por el príncipe Aga Khan, a partir de una naturaleza poco alterada y una reinterpretación de la arquitectura vernácula por parte de Luigi Vietti, da lugar a un escenario turístico tan artificial como cualificado.

En "Prácticas del paisajismo francés: La construcción del proyecto del paisaje en el plan turístico Maspalomas Costa Canaria. 1961”, Iván Álvarez analiza a fondo un proyecto bien singular, el primer plan de ordenación de Maspalomas, diseñado por un grupo de arquitectos franceses (AS ATEA+SETAP). Éste constituye uno de los pioneros que emplean el valor del paisaje para ordenar el territorio costero. La estrecha relación de sus autores con otras intervenciones urbanas y paisajísticas en Francia, se convierten en el principal argumento de su investigación. 
Finalmente recogemos en "César Manrique: La conciencia del paisaje", un texto que aborda precisamente la relación entre turismo, paisaje y urbanismo, desde la perspectiva de los paisajes culturales. Forma parte del catálogo de una exposición dedicada a César Manrique, que tuve el encargo de comisariar. En Lanzarote se sientan las bases de una propuesta territorial singular y diferenciada en el archipiélago canario, origen del renombre que este destino goza aún hoy. Sin tratarse de un plan en sentido estricto, nace de la concepción de un proyecto turístico singular basado en un paisaje telúrico, tan frágil como extraordinario. Los instrumentos esenciales son la creatividad de César Manrique y el liderazgo del gobierno insular.

En la exposición y en el artículo se pretende indagar en los orígenes de la preocupación del artista por Lanzarote, y mostrar el peso que sus tierras y sus gentes tienen en tan importante obra pictórica. Pero fundamentalmente se quiere destacar su compromiso con el paisaje, su lucha por cambiar nuestra percepción del mismo, por exaltar la belleza de una naturaleza árida y el esfuerzo de los constructores de la isla, capaces de sobrevivir en un territorio tan adverso, y que paciente y esforzadamente, lo van modelando para hacerlo vivible.

César Manrique nos enseña a luchar por el paisaje, nos anima a respetar nuestro territorio y nuestra cultura, que es, en definitiva, respetarnos a nosotros mismos, nos demuestra como el trabajo con el paisaje puede llegar a suponer el mejor reclamo turístico. Y a pesar de que parte de su legado haya sido alterado, sigue siendo la demostración palpable de la posibilidad de desarrollar un modelo turístico que sitúa el paisaje como el principal de sus activos. 


\section{BIBLIOGRAFÍA}

AA.VV. Designing the Llobregat Corridor. Cultural Landscape and Regional Development. Projectant l'eix del Llobregat. Paisatge cultural i desenvolupament regional. Barcelona, Massachusetts Institute of Technology y Universitat Politècnica de Catalunya, 2001.

AA.VV. César Manrique. La Conciencia del paisaje. Gráficas Sabater. Santa Cruz de Tenerife, 2013.

BARBA, R. y PIE, R. Estudis urbans. Castell-Platja d'Aro-Sant Feliu de Guixols-Santa Cristina d'Aro 1981. Barcelona, Departament de Política Territorial i Obres Públiques, Generalitat de Catalunya, 1983.

FERRER, A. y SABATÉ, J. Estudis urbans. Torroella de Montgrí-L'Estartit 1981. Barcelona, Departament de Política Territorial i Obres Públiques, Generalitat de Catalunya, 1983.

SABATÉ, J. Tourism land use management in Tenerife's island plan (PIOT): Tourism, landscape and agriculture terraces, en Flora Maria Díaz Pérez (ed) Competitive Strategies and Policies for Tourism destinations. Quality, innovation and promotion (pp. 159-170). Nova Science Publishers, Inc. New York, 2010.

SABATÉ, J. y CCRS. Plan Insular de Ordenación del Territorio. PIOT Avance. Santa Cruz de Tenerife, Excmo. Cabildo Insular de Tenerife, 1994. 